\title{
Current Concepts in Genitourinary Oncology: GU-ASCO 2015
}

\section{Anil Kapoor, MD, FRCSC}

Professor of Surgery (Urology), McMaster University, Associate Editor (Oncology), Canadian Urological Association Journal (CUAJ), Hamilton, ON

Cite as: Can Urol Assoc J 2015;9(5-6-Suppl3):S147. http://dx.doi.org/10.5489/cuaj.2993 Published online June 15, 2015.

\section{$\mathrm{T}$} he outstanding science presented at the annual Genitourinary Cancers Symposium-American Society of Clinical Oncology (GU-ASCO) held in Orlando, Florida on February 26-28, 2015, continues to reinforce that this annual meeting is the premier symposium for genitourinary $(\mathrm{GU})$ oncology cutting-edge research. The following congress report summarizes some of the key research presented at the meeting, though is by no means comprehensive. We have highlighted specific research relevant to GU urologists, medical oncologists, and radiation oncologists, and focused on updates in prostate cancer and kidney cancer. We appreciate that this supplement is made possible through the generous support of Astellas Oncology and Novartis Oncology.

We hope you find the information useful and relevant, and welcome any feedback on this report.

Competing interests: Dr. Kapoor is a member of the Speakers Bureau for Pfizer and Novartis. He has also received grants from Pfizer, GSK, Novartis, and Amgen. He is currently participating in a clinical trial with NCIC, Pfizer, GSK, Novartis, and Amgen.

Correspondence: Dr. Anil Kapoor, McMaster Institute of Urology, St. Joseph's Healthcare, Hamilton, ON; akapoor@mcmaster.ca 